\title{
Uterocervical Angle and Cervical Length as a Tool to Predict Preterm Birth in Threatened Preterm Labor
}

This article was published in the following Dove Press journal: International Journal of Women's Health

\author{
Sireethorn Luechathananon (iD) \\ Metha Songthamwat (iD) ${ }^{2}$ \\ Sukanya Chaiyarach' \\ 'Department of Obstetrics and \\ Gynaecology, Faculty of Medicine, Khon \\ Kaen University, Khon Kaen, Thailand; \\ ${ }^{2}$ Department of Obstetrics and \\ Gynaecology, Udonthani Hospital, Udon \\ Thani, Thailand
}

Correspondence: Sukanya Chaiyarach Email sukanyatanoorat@hotmail.com
Objective: To evaluate the diagnostic performance of uterocervical angle (UCA) and UCA with cervical length (CL) in predicting preterm delivery in threatened preterm labor.

Methods: A multicenter prospective observational cohort study was conducted in 160 pregnant women having threatened preterm labor at Srinagarind and Udonthani Hospitals in Thailand between March 2019 and June 2020. Researchers measured UCA and CL by transvaginal ultrasonography. Medical records were reviewed for patient characteristics, and patients were followed up until the date of delivery to assess for the outcome of preterm birth. The cut-off point of UCA was determined from receiver operating characteristic curve analysis. The sensitivity, specificity, likelihood ratio, positive and negative predictive values (PPV and NPV) of UCA and of UCA with CL for predicting preterm birth were determined.

Results: The incidence of preterm birth in women having threatened preterm labor was $27 \%$. The sensitivity, specificity, PPV and NPV of UCA $\geq 110.97$ degrees for predicting preterm birth were $65.1 \%, 43.6 \%, 29.8 \%$ and $77.3 \%$, respectively. The sensitivity, specificity, PPV and NPV of $\mathrm{UCA} \geq 110.97$ degrees with $\mathrm{CL}<3.4$ centimeters for predicting preterm birth were $48.8 \%, 68.4 \%$, $36.2 \%$ and $78.4 \%$. The specificity and NPV of UCA with CL were higher than for UCA alone. Conclusion: With adequate sensitivity and high NPV, UCA by TVS can be supplemented with CL measurement in threatened preterm labor management to increase the diagnostic performance for predicting preterm birth.

Keywords: uterocervical angle, cervical length, preterm birth, threatened preterm labor

\section{Introduction}

Preterm birth is one of the most important obstetric problems. According to the American College of Obstetricians and Gynecologists (ACOG), preterm delivery accounts for $70 \%$ of early neonatal deaths and $25-50 \%$ of infant deaths aged less than one year. ${ }^{1}$ In the United States, the prevalence of preterm birth is $12 \%{ }^{2}$, which is similar to the number in our center. The World Health Organization reports that about a half of all preterm births are due to spontaneous preterm labor. ${ }^{1}$

Threatened preterm labor is labor pains with the absence of cervical changes occurring before 37 weeks of pregnancy. ${ }^{3}$ Around $25-30 \%$ of threatened preterm labor progresses to preterm delivery. ${ }^{4}$ Data from our center, a university hospital in the northeast of Thailand, that was collected in 2018 showed the number of pregnancies presenting labor pain at a gestational age less than 37 weeks was 431 patients. Of these, 286 patients $(66.36 \%)$ were categorized as threatened preterm labor and 52 of these 286 patients $(18.18 \%)$ had a preterm birth. 
Currently, there are no guidelines for the management of threatened preterm labor. In Thailand, a vaginal or speculum examination is performed for any pregnancy less than 37 weeks of gestation with suspected labor pain to evaluate cervical dilatation and assess for preterm and threatened preterm labor. Although ACOG does not recommend using tocolytic drugs in pregnancies presenting with labor pain and cervical dilatation $<2 \mathrm{~cm}^{5}$, one study suggested that in pregnancies with labor pain and cervical dilatation $<3 \mathrm{~cm}$ that did not receive tocolytic agents, $21.2 \%$ of births were preterm, $14.7 \%$ of newborns required admission to the neonatal intensive unit and 10 neonates died. ${ }^{6}$ An effective tool to differentiate false labor pains from the early stages of preterm labor is needed.

Data from several studies suggest that preterm labor can be predicted by assessing cervical conditions such as cervical length (CL), ${ }^{7-9}$ and fetal fibronectin. ${ }^{6,9}$ These are recommended by ACOG as part of preterm labor management. Recently, several techniques for assessing threatened preterm labor such as sonoelastography, ${ }^{10,11}$ acoustic radiation force impulse or shear wave velocity, ${ }^{12}$ and fetal adrenal gland biometry have been published, ${ }^{13}$ however, these techniques require advanced technology and are unsuitable for general use. Another novel cervical assessment is measurement of the uterocervical angle (UCA) by transvaginal ultrasonography (TVS), which has been reported as a high-performance screening tool for predicting preterm birth during the second trimester of gestation. $^{14,15}$ In addition, the UCA has been shown to become more acute following insertion of a vaginal pessary to prevent preterm birth in patients at risk for spontaneous preterm birth. ${ }^{16,17}$ It is a simple, inexpensive method that is safe for both the fetus and mother. However, there is no prior evidence of the use of UCA measurement in the management of threatened preterm labor. ${ }^{15,18,19}$ Therefore, the purpose of this study is to evaluate whether UCA measured by TVS can predict the risk of preterm birth in threatened preterm labor and to identify associated factors of preterm birth in threatened preterm labor.

\section{Materials and Methods Study Design}

A multicenter prospective observational cohort study was conducted and reported according to the Standards for Reporting of Diagnostic Accuracy Studies (STARD). ${ }^{20}$

\section{Participants and Settings}

Women with threatened preterm labor, who were admitted to either the labor room at Srinagarind Hospital between March 2019 and June 2020 or the labor room at Udonthani Hospital between September 2019 and March 2020, were counseled and invited to participate in this study.

Eligibility criteria included diagnosis with threatened preterm labor (defined as a condition which is in regular uterine contractions occur at least 1 time in 10 minutes and persist for more than 30 minutes before completion of 37 weeks of gestation without dilatation of the cervix ${ }^{3,21}$ ), a singleton gestation, and aged more than 18 years. Women were excluded from the study if they had placenta previa, any contact bleeding pathologies including endocervical polyp, infection, and bleeding tumors, and if the image after performing TVS was considered suboptimal due to inappropriate anatomy; the anteriorly lower uterine segment or the cervical canal was excessively compressed by any masses. Women were also excluded from analysis if they withdrew from the study, if the delivery outcome could not be obtained, and if they experienced medically indicated preterm birth including severe intrauterine growth restriction, prolonged preterm premature rupture of membranes, preeclampsia with severe features and nonreassuring fetal status.

\section{Sample Size}

The sample size was calculated by using the diagnostic study formula ${ }^{22}$ as follows: and n4Studies application. Based on a sensitivity of $80 \%,{ }^{14}$ an error of 0.18 , and a prevalence of 0.12 , the sample size was 160 patients.

\section{Test Methods}

After obtaining the consent of participants, demographic data were collected via antenatal medical record review. Transvaginal images were obtained with GE Logiq C5 Premium and GE Voluson P6 Ultrasound Machine with 7.5-10 MHz transvaginal probe. The UCA is a TVS marker which defines the angle between the lower uterine segment and the cervical canal (Figure 1). After obtaining an appropriate view of the cervix, the anterior uterine wall is visualized. The internal and external cervical ora, including the isthmus, are identified and a line between them is drawn. A second line is drawn parallel to the lower aspect of the anterior uterine wall, passing through the internal cervical os. The angle created by the two lines at the internal os is the UCA. ${ }^{9}$ All UCA and CL measurements were done by 


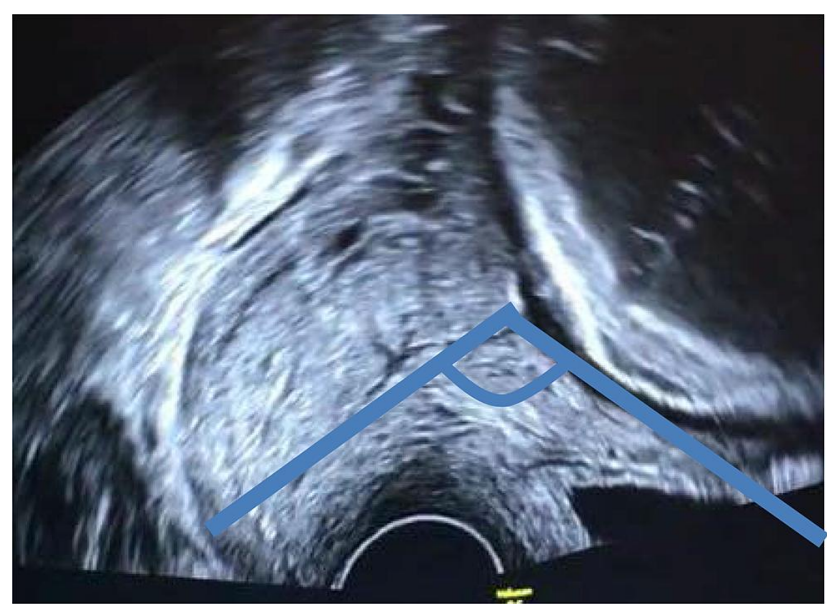

Figure I UCA by TVS.

obstetricians or residents (researchers) that were trained and assessed for reliability. Analysis of the intraclass correlation coefficient showed that inter-rater reliability was greater than 0.75. Researchers measured and recorded UCA and CL three times with real-time angle calculation by the ultrasound device, then the mean of these values was calculated. $^{23}$ The UCA and CL data were concealed from hospital ward staff. The participants were treated and followed up until delivery according to the hospital's protocol. Pregnancy and neonatal outcomes were collected by medical record review and telephone interview.

\section{Analysis}

STATA version 10.0 was used for statistical analysis. The demographic data were reported by frequency, percentage, mean with standard deviation and $95 \%$ confidence interval, and median with interquartile range (IQR). Preterm birth was defined as $<37$ weeks for reference. The diagnostic performance of different cut-off values of UCA, CL, and UCA with CL were analyzed and receiver operating characteristic (ROC) curves were developed to determine an optimal UCA cut-off value for the best prediction of preterm birth outcome. The Kolmogorov-Smirnov test was used to determine the distribution of data. For possible associated factors of preterm birth, the Student's $t$-test for comparison of means was used for normally distributed continuous variables. The Wilcoxon Rank sum test was used for nonnormally distributed continuous variables. When $p$ value from bivariate analysis $<0.2$, then multivariable adjusted analysis were calculated. Logistic regression analysis, Pearson's Chi-square and Fisher exact test were used for comparison of discrete data. A $p$ value $<0.05$ was defined as statistically significant.

\section{Ethical Consideration}

Written informed consent was obtained from all participants and they were fully informed about the study. Institutional review board approval and institutional ethics committee approval was given to the study which was also reviewed by the Khon Kaen University Ethics Committee for Human Research based on the Declaration of Helsinki and the $\mathrm{ICH}$ Good Clinical Practice Guidelines (HE611466) and The Ethical Review Committee for Research in Human Subjects Udonthani Hospital (I062/ 2562). The study was registered with the Thai Clinical Trials Registry (TCTR20200719002).

\section{Results}

\section{Demographics}

There were 160 patients in this study. Of these 160 patients, 121 patients $(75.6 \%)$ were from Srinagarind Hospital and 39 patients $(24.4 \%)$ were from Udonthani Hospital. There were no cases of failure to measure UCA. The demographic characteristics are shown in Table 1 . The mean age of patients was 29.1 years (standard deviation, $\mathrm{SD}=6.1$ years). One hundred and seventeen patients had term births, while 43 patients had preterm births. There were no statistical differences between the two groups in patient characteristics. The median CL of the preterm group was significantly shorter than that of the term group by $0.4 \mathrm{~cm}(\mathrm{p}=0.03)$. The median UCA was 113 degrees in both groups $(p=0.93)$; however, the widest UCA of the preterm group was more than the widest UCA of the term group.

\section{The Use of UCA as a Screening Tool for Preterm Birth}

The incidence of preterm birth was $27 \%$. The optimal UCA cut-off point for predicting preterm birth from the ROC curve was 110.97 degrees (Figure 2). Of the 43 patients with preterm birth, 28 patients $(65.1 \%)$ had UCA $\geq 110.97$ degrees. Of the 117 patients with term birth, 51 patients (43.6\%) had UCA < 110.97 degrees. The sensitivity, specificity, positive predictive value (PPV) and negative predictive value (NPV) for UCA $\geq 110.97$ degrees preterm birth screening were $65.1 \%$ (95\% confidence interval (CI); 0.49-0.79), 43.6\% (95\% CI; 0.34-0.53), 29.8\% (95\% CI; 0.21-0.40), and $77.3 \%(95 \% \mathrm{CI} ; 0.65-0.87)$ respectively (Table 2$)$. The area under the ROC curve was 0.50 . 
Table I Patient Characteristics

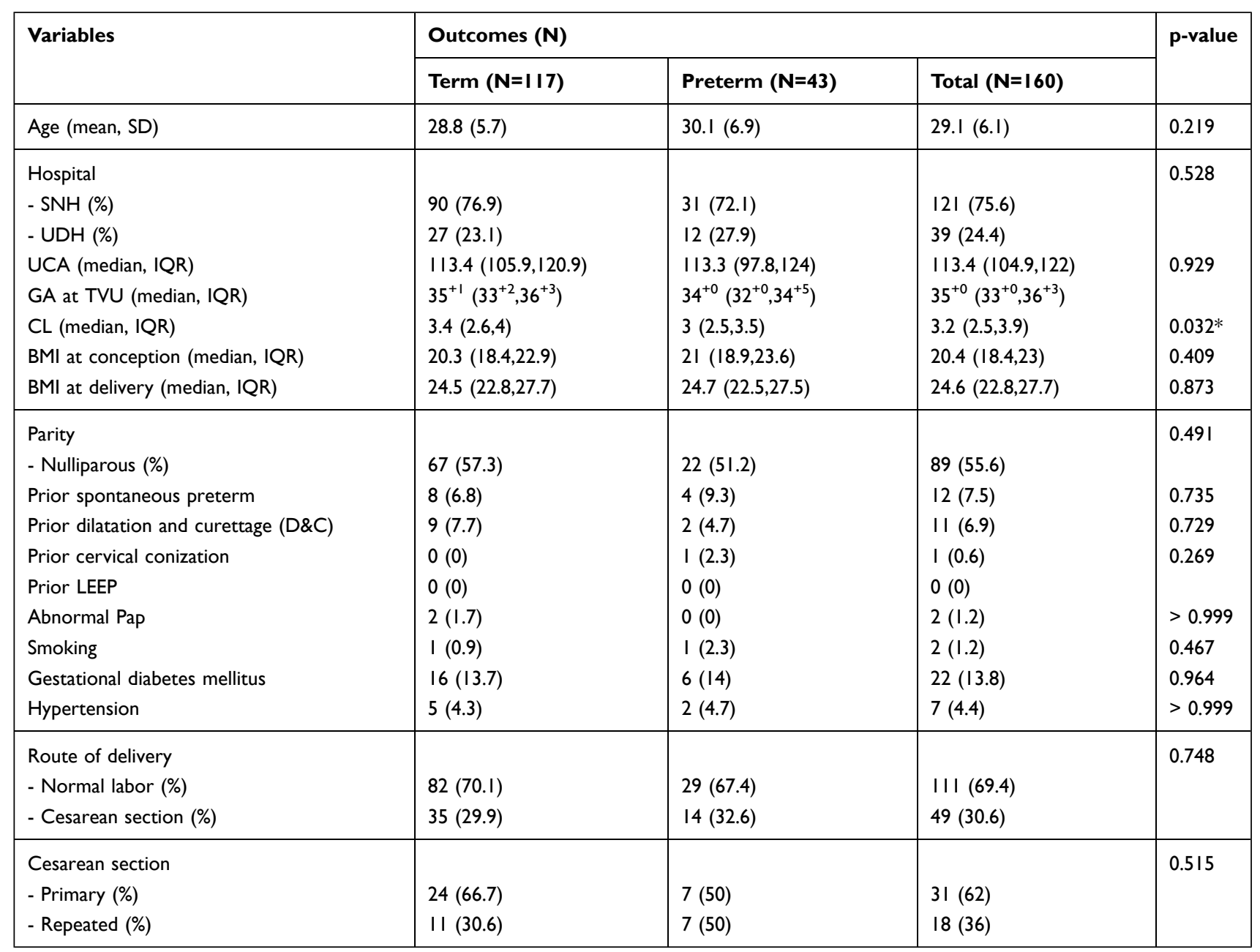

Note: *Statistically significant at an alpha level of 0.05 .

\section{The Use of $C L$ as a Screening Tool for Preterm Birth}

The optimal CL cut-off point for predicting preterm birth from the ROC curve was 3.4 centimeters (Figure 2). The diagnostic performance of $\mathrm{CL}<3.4 \mathrm{~cm}$ for predicting preterm birth had sensitivity, specificity, PPV and NPV of $72.1 \%, 46.2 \%, 33 \%$ and $81.8 \%$, respectively.

\section{The Use of UCA and CL as a Screening Tool for Preterm Birth}

Table 3 shows the performance analysis of using both UCA $\geq 110.97$ degrees and CL $<3.4 \mathrm{~cm}$ for preterm birth prediction. The data indicate that the use of both UCA $\geq 110.97$ degrees and $\mathrm{CL}<3.4 \mathrm{~cm}$ increased the positive predictive value (PPV) and positive likelihood ratio (PLR) for the prediction of preterm birth to $36.2 \%$ and 1.54 , respectively.

A logistic regression analysis of UCA alone demonstrated that UCA values were not different between the preterm birth and term birth groups $(\mathrm{p}=0.93)$, while the same analysis of CL revealed the groups to have different CL values $(\mathrm{p}=0.03)$ (Table 1$)$.

\section{Discussion}

This is the first prospective observational cohort study to investigate the diagnostic performance of TVS-UCA measurement in pregnancy with threatened preterm labor as a predictor for preterm birth. Our findings revealed that the use of UCA from TVS $\geq 110.97$ degrees as a predictor for preterm birth in threatened preterm labor patients had sensitivity and specificity of $65.1 \%$ and $43.6 \%$, respectively. In reviewing the literature about the evaluation of TVS-UCA as a screening tool for preterm birth $(<37$ weeks), one study reported that TVS-UCA $>95$ degrees and UCA $>105$ degrees, measured in the second trimester, were significantly associated with preterm birth $<37$ weeks and preterm birth $<34$ weeks, respectively. ${ }^{14}$ The TVS- 


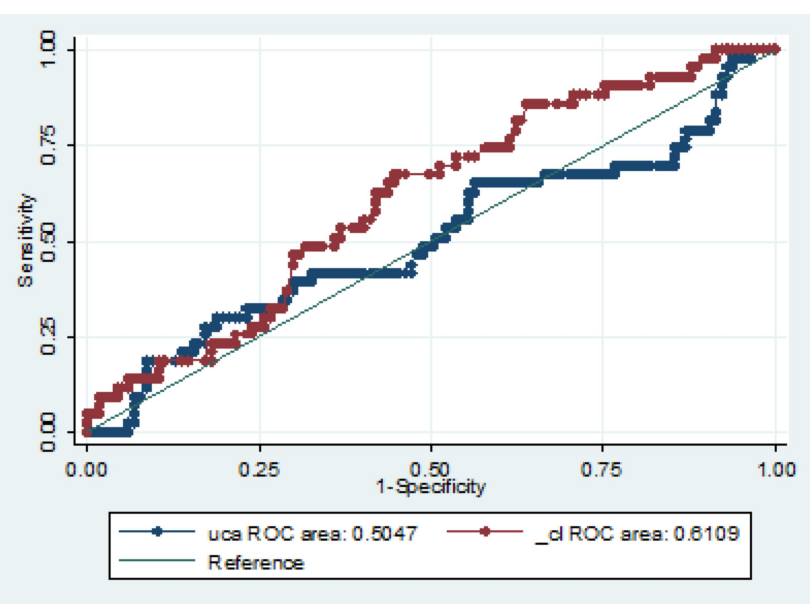

Figure 2 The receiver operating characteristic (ROC) curve between UCA and $C L$ and preterm birth.

UCA of $>95$ degrees in that study had a sensitivity of $80 \%$ and specificity of $53 \%,{ }^{14}$ both of which are higher than in this study. These results seem to be consistent with other research in first and second trimester pregnancies that found UCA was a useful screening tool for predicting preterm delivery. ${ }^{15,18}$ The NPV of UCA $>110.97$ degrees in our study was $77.3 \%$ (range $65.3 \%-86.7 \%$ ), which implies that a UCA $<110.97$ degrees in pregnancies with threatened preterm labor has low likelihood of preterm birth.

TVS-CL is a commonly used cervical marker in preterm birth prediction in both second and third

Table 2 Odds Ratios and Associated 95\% Confidence Intervals for Independent Predictors of Preterm Birth in Logistic Regression Model $(\mathrm{N}=160)$

\begin{tabular}{|l|l|l|l|}
\hline Variables & $\begin{array}{l}\text { Odds } \\
\text { Ratio }\end{array}$ & $\mathbf{9 5 \%} \mathbf{C l}$ & p-value \\
\hline $\mathrm{CL}<3.4 \mathrm{~cm}$ & 1.92 & $0.58-6.42$ & 0.29 \\
$\mathrm{UCA} \geq \mathrm{II} 0.97$ degrees & 1.21 & $0.34-4.28$ & 0.77 \\
$\mathrm{UCA} \geq \mathrm{II} 0.97$ degrees and & 1.22 & $0.26-5.80$ & 0.80 \\
$\mathrm{CL}<3.4 \mathrm{~cm}$ & & & \\
\hline
\end{tabular}

trimesters. ${ }^{8,9,14,24,25}$ Data from the current study found that the diagnostic performance of TVS-CL was higher than TVS-UCA. However, the combination of both parameters could increase the accuracy of cervical condition assessment for preterm prediction. While the sensitivity of TVS-UCA with TVS-CL decreased, the specificity was higher. This finding could be applicable for diagnosis, further study is needed. Determination of the TVS-UCA is easy to perform without additional cost from TVS-CL measurement. We propose that the high NPV of TVS-UCA with TVS-CL means it could be used in clinical practice in threatened preterm labor management to support the judgement of admission and use of tocolytic agents.

The mean UCA (113.4 degrees) in the current study was more than that reported in earlier studies. A previous prospective cohort analysis that studied threatened preterm labor between the $20^{\text {th }}$ and $31^{\text {st }}$ weeks reported an average UCA of 103 degrees and the mean UCAs in the preterm and term groups did not differ significantly $(\mathrm{P}=0.924) .{ }^{26}$ Another prospective study recorded TVS-UCA with TVS$\mathrm{CL}$ as a routine screening between the $18^{\text {th }}$ and $23^{\text {rd }}$ weeks of gestation. The mean UCA in the second trimester was 101.7 degrees (95\% CI: 87-116.4) in the spontaneous preterm deliveries and 103.6 degrees (95\% CI: 101.1-106.2) in the deliveries at term. ${ }^{27}$ This implies that TVSUCA depends on the gestational age at the time of study and it increases with advanced gestational age.

The cut-off value of TVS-UCA (110.97 degrees) from the current study is different from previous studies ${ }^{14,15}$ that used cut-off values at 95 and 105 degrees. This might result from differences in trimesters and participant's characteristics. Our participants were in threatened preterm labor and mostly in the third trimester. Cervical shape and length gradually change from the first to the third trimesters. The mean $\mathrm{CL}$ has been reported to shorten from $38.30 \pm 7.28 \mathrm{~mm}$ at 20 weeks to $37.03 \pm 4.82 \mathrm{~mm}$ at 28 weeks gestation. ${ }^{28}$ The UCA is also suspected to change with the gestational age; however, normal values of UCA in the third trimester have not been reported.

Table 3 Diagnostic Performance of Uterocervical Angle and Cervical Length for Prediction of Preterm Delivery

\begin{tabular}{|c|c|c|c|c|c|c|c|}
\hline Parameters & Sensitivity & Specificity & PPV & NPV & PLR & NLR & $\begin{array}{l}\text { ROC } \\
\text { Area }\end{array}$ \\
\hline UCA $\geq 110.97$ degrees & $65.1 \%(49.1-79.0)$ & $43.6 \%(34.4-53.1)$ & $29.8 \%(20.8-40.1)$ & $77.3 \%(65.3-86.7)$ & 1.15 & 0.8 & 0.544 \\
\hline $\mathrm{CL}<3.4 \mathrm{~cm}$ & $72.1 \%(72.1-56.3)$ & $46.2 \%(36.9-55.6)$ & $33 \%(23.6-43.4)$ & $81.8 \%(70.4-90.2)$ & 1.34 & 0.61 & 0.591 \\
\hline $\begin{array}{l}U C A \geq 110.97 \text { degrees and } \\
C L<3.4 \mathrm{~cm}\end{array}$ & $48.8 \%(33.3-64.5)$ & $68.4 \%(59.1-76.7)$ & $36.2 \%(24.0-49.9)$ & $78.4 \%(69.2-86)$ & 1.54 & 0.75 & 0.586 \\
\hline
\end{tabular}


This study has some limitations. The sample size of this study was calculated to determine the sensitivity of UCA, therefore a larger sample size would be needed to identify the difference between TVS-UCA of preterm and term birth groups. This caused a non-normal distribution of UCA and CL values in this study and non-parametric statistics were necessary to conduct the analysis. This study did not categorize preterm birth into early preterm birth and late preterm birth. Therefore, it might not be possible to compare the results with previous studies that focused on TVS during the second trimester of pregnancy.

\section{Conclusion}

With adequate sensitivity and high NPV, the TVS-UCA measurement can be considered as a useful tool for predicting preterm birth in threatened preterm labor. Moreover, both UCA and CL can be used to predict risks for preterm birth and support clinicians' decisions on using tocolytic agents in threatened preterm labor.

\section{Acknowledgment}

The authors would like to thank the lecturers in the Department of Obstetrics and Gynaecology, Faculty of Medicine, Khon Kaen University for all useful suggestions regarding this study. In addition, the authors would like to acknowledge Dr. Glenn Borlace for editing the MS via the publication clinic at Khon Kaen University. The authors would also like to thank Kaewjai Thepsuthammarat, Clinical Epidemiology Unit, Srinagarind Hospital, Khon Kaen University for biostatistical consultation.

\section{Funding}

This study was supported by the Faculty of Medicine, Khon Kaen University under Grant IN62211.

\section{Disclosure}

The authors declare no conflicts of interest for this work.

\section{References}

1. American College of Obstetricians and Gynecologists' Committee on Practice Bulletins-Obstetrics. ACOG practice bulletin no. 127: management of preterm labor. Obstet Gynecol. 2012;119(6):1308-1317. doi:10.1097/AOG.0b013e31825af2fo.

2. World Health Organization. Born Too Soon: The Global Action Report on Preterm Birth. Vol. 13. 2012. Available from: http://whqlibdoc.who.int/ publications/2012/9789241503433_eng.pdf. Accessed January 2, 2021.

3. Maternal Child Health Board, Professional Standards Subcommittee. RTCOG Clinical Practice Guideline the Management of Preterm Labour and Preterm Premature Rupture of Membranes.; 2015.
4. Chawanpaiboon S, Kanokpongsakdi S. Comparison of Nifedipine and Bed Rest for Inhibiting Threatened Preterm Labour. Gynecol Obs. 2012;2:131. doi:10.4172/2161-0932.1000131

5. American College of Obstetricians and Gynecologists' Committee on Practice Bulletins-Obstetrics. Practice Bulletin No. 171: management of Preterm Labor. Obstet Gynecol. 2016;128(4):e155. doi:10.1097/AOG.0000000000001711.

6. Peaceman AM, Andrews WW, Thorp JM, et al. Fetal fibronectin as a predictor of preterm birth in patients with symptoms: A multicenter trial. Am J Obstet Gynecol. 1997;177(1):13-18. doi:10.1016/S00029378(97)70431-9

7. McIntosh J, Feltovich H, Berghella V, Manuck T. The role of routine cervical length screening in selected high- and low-risk women for preterm birth prevention. Am J Obstet Gynecol. 2016;215(3):B2-B7. doi:10.1016/j.ajog.2016.04.027

8. Berghella V, Palacio M, Ness A, Alfirevic Z, Nicolaides KH, Saccone G. Cervical length screening for prevention of preterm birth in singleton pregnancy with threatened preterm labor: systematic review and meta-analysis of randomized controlled trials using individual patient-level data. Ultrasound Obstet Gynecol. 2017;49 (3):322-329. doi:10.1002/uog. 17388

9. Son M, Miller ES. Predicting preterm birth: cervical length and fetal fibronectin. Semin Perinatol. 2017;41(8):445-451. doi:10.1053/j. semperi.2017.08.002

10. Światkowska-Freund M, Pankrac Z, Preis K. Intra- and inter-observer variability of evaluation of uterine cervix elastography images during pregnancy. Ginekol Pol. 2014;85(5):360-364. doi:10.17772/gp/1740

11. Swiatkowska-Freund M, Preis K. Cervical elastography during pregnancy: clinical perspectives. Int J Womens Health. 2017;9:245-254. doi:10.2147/IJWH.S106321

12. Agarwal A, Agarwal S, Chandak S. Role of acoustic radiation force impulse and shear wave velocity in prediction of preterm birth: a prospective study. Acta Radiol. 2018;59(6):755-762. doi:10.1177/ 0284185117730689

13. Agarwal S, Agarwal A, Joon P, Saraswat S, Chandak S. Fetal adrenal gland biometry and cervical elastography as predictors of preterm birth: A comparative study. Ultrasound. 2018;26(1):54-62. doi: $10.1177 / 1742271 \mathrm{X} 17748515$

14. Dziadosz M, Bennett TA, Dolin C, et al. Uterocervical angle: a novel ultrasound screening tool to predict spontaneous preterm birth. Am $J$ Obstet Gynecol. 2016;215(376):e1-376.e7. doi:10.1016/j. ajog.2016.03.033

15. Daskalakis G, Theodora M, Antsaklis P, et al. Assessment of Uterocervical Angle Width as a Predictive Factor of Preterm Birth: A Systematic Review of the Literature. Biomed Res Int. 2018;2018:2018. doi:10.1155/2018/1837478

16. Arabin B, Halbesma JR, Vork F, Hübener M, Van Eyck J. Is treatment with vaginal pessaries an option in patients with a sonographically detected short cervix? J Perinat Med. 2003;31(2):122-133. doi:10.1515/JPM.2003.017

17. Cannie MM, Dobrescu O, Gucciardo L, et al. Arabin cervical pessary in women at high risk of preterm birth: A magnetic resonance imaging observational follow-up study. Ultrasound Obstet Gynecol. 2013;42(4):426-433. doi:10.1002/uog.12507

18. Sochacki-Wójcicka N, Wojcicki J, Bomba-Opon D, Wielgos M. Anterior cervical angle as a new biophysical ultrasound marker for prediction of spontaneous preterm birth. Ultrasound Obstet Gynecol off J Int Soc Ultrasound Obstet Gynecol. 2015;46(3):377-378. doi:10.1002/uog.14801

19. Williams JW, Cunningham FG, Leveno KJ, Bloom SL, Spong CY, Dashe JS. Williams Obstetrics. 25th ed. McGraw-Hill Education Medical; 2018. https://accessmedicine.mhmedical.com/book.aspx? bookid=1918. Accessed January 2, 2021.

20. Cohen JF, Korevaar DA, Altman DG, et al. STARD 2015 guidelines for reporting diagnostic accuracy studies: explanation and elaboration. BMJ Open. 2016;6(11):11. doi:10.1136/bmjopen-2016-012799 
21. Songthamwat S, Na Nan C, Songthamwat M. Effectiveness of nifedipine in threatened preterm labor: a randomized trial. Int $J$ Womens Health. 2018;10:317-323. doi:10.2147/IJWH.S159062

22. Rosner B. Fundamentals of Biostatistics. Thomson-Brooks/Cole. 2006.

23. Andrade S, Andrade F, Araujo Júnior E, Pires C, Mattar R, Moron A. Assessment of Length of Maternal Cervix between 18 and 24 weeks of Gestation in a Low-Risk Brazilian Population. Rev Bras Ginecol e Obs/ RBGO Gynecol Obstet. 2017;39(12):647-652. doi:10.1055/s-00371608617

24. Boelig R, Roman A, Berghella V, Dugoff L. 697: second trimester cervical length $\leq 11 \mathrm{~mm}$ is associated with asymptomatic manual cervical dilation and poor obstetric outcomes. Am J Obstet Gynecol. 2018;218:S418-S419. doi:10.1016/j.ajog.2017.11.227

25. Boelig RC, Hecht N, Berghella V. 698: cervical length $<15 \mathrm{~mm}$ is the most important risk factor for early preterm birth in women with short cervix treated with vaginal progesterone. Am J Obstet Gynecol. 2018;218(1): S419-S420. doi:10.1016/j.ajog.2017.11.228
26. Gründler K, Gerber B, Stubert J. Uterocervical angle as a predictor of preterm birth on a high-risk collective between 20 and 31 weeks of gestation: A cohort analysis. Acta Obstet Gynecol Scand. 2020;99 (11):1527-1533. doi:10.1111/aogs.13955

27. Llobet F, Sanz H, Fernández C, et al. Second Trimester Uterocervical Angle as a Predictor of Spontaneous Preterm Birth: A Prospective Study. 16th World Congress in Fetal Medicine; 2017.

28. Jafari-Dehkordi E, Adibi A, Sirus M. Reference range of the weekly uterine cervical length at 8 to 38 weeks of gestation in the center of Iran. Adv Biomed Res. 2015;4:115. doi:10.4103/2277-9175.157839

International Journal of Women's Health

\section{Publish your work in this journal}

The International Journal of Women's Health is an international, peerreviewed open-access journal publishing original research, reports, editorials, reviews and commentaries on all aspects of women's healthcare including gynecology, obstetrics, and breast cancer. The manuscript management system is completely online and includes a very quick and fair peer-review system, which is all easy to use. Visit http://www.dovepress.com/testimonials.php to read real quotes from published authors. 